\title{
EVALUATION OF CATECHOL AMINE LEVELS IN RENAL INSUFFICIENCY
}

\author{
By M. SEREF ZILELI, JAMES T. HAMLIN, III, FRITZ W. REUTTER, AND \\ DALE G. FRIEND \\ (From the Departments of Medicine, Harvard Medical School and Peter Bent Brigham Hospital, \\ Boston, Mass.)
}

(Submitted for publication August 28, 1957; accepted November 14, 1957)

The estimation of epinephrine (E) and norepinephrine (NE) in plasma and urine has become important as a procedure in physiological research and as an aid in the diagnosis of pheochromocytoma. With the development of fluorometric procedures the chemical estimation of $\mathrm{E}$ and $\mathrm{NE}$ in biological fluids and tissues was made possible.

The fluorometric procedures used most commonly are modifications of the trihydroxyindole method of Lund (1) and the ethylenediamine (EDA) condensation method of Weil-Malherbe and Bone $(2,3)$. The trihydroxyindole method is not sensitive enough to permit measurements of $\mathrm{E}$ and $\mathrm{NE}$ in small amounts of normal peripheral plasma (1), and its practical usefulness is limited to the assay of urine. The sensitivity of the EDA condensation method is such that extremely small amounts of $\mathrm{E}$ and $\mathrm{NE}$ can be measured; however, it is not as specific as the trihydroxyindole method and will detect phenolic compounds other than $\mathrm{E}$ and NE (4).

While employing the EDA condensation method as an aid in the diagnosis of pheochromocytoma, we have observed, in some individuals with renal insufficiency who later were found not to have a pheochromocytoma, levels of $\mathrm{E}$ and $\mathrm{NE}$ much higher than those which occur in normal patients. The purpose of the present study was to determine whether the high levels of $E$ and NE frequently observed in patients with renal insuffciency are true values or are due to the presence of substances which interfere with the EDA method and produce false high values of $E$ and NE.

The presence of large amounts of these substances may be due to an abnormal or increased production of $\mathrm{E}, \mathrm{NE}$ or interfering compounds, or an inability on the part of the kidneys to excrete the normal amounts of these substances present in the blood. Among possible interfering substances which occur in abnormal amounts in the blood of patients with renal insufficiency are urea, creatinine, uric acid and phenolic compounds. Of these, the phenolic compounds are most likely to be involved.

The phenols are excreted in both free and conjugated forms, with a normal daily output in the urine of 200 to $500 \mathrm{mg}$. (5). They are derived mainly from bacterial putrefaction of aromatic amino acids in the intestine. A minor portion comes from the presence of sex hormones, epinephrine, norepinephrine and tyrosine in the blood. The normal blood levels calculated as phenol range from 1 to $2 \mathrm{mg}$. per $100 \mathrm{ml}$., whereas in uremic patients they may reach 6 to $10 \mathrm{mg}$. per $100 \mathrm{ml}$. (6). The importance of these compounds in the pathogenesis of uremic symptoms has been reviewed by Harrison and Mason (7).

In order to determine whether the presence of large amounts of phenolic compounds in the plasma of patients with renal insufficiency can account for the high levels of $\mathrm{E}$ and $\mathrm{NE}$ as measured by the EDA condensation method, the effect of various phenolic compounds on this method and the trihydroxyindole method was investigated, and the specificity of these two fluorometric procedures for estimating catechol amines was compared. Plasma $\mathrm{E}$ and $\mathrm{NE}$ levels were assayed by both methods in normal individuals and patients with renal disease. The high $\mathrm{E}$ and $\mathrm{NE}$ levels found in the patients with renal insufficiency were then evaluated in the light of information developed from the differences in specificity established for the two methods.

\section{METHODS}

Standard solutions containing monohydroxy-, dihydroxy- and trihydroxyphenyl compounds which might be expected to occur in the blood were prepared. Known amounts of these were added to pooled heparinized plasma for recovery determinations. Extraction from plasma 
TABLE I

Compounds which produce fluorescence with ethylenediamine and are adsorbed from plasma by alumina

\begin{tabular}{|c|c|c|c|c|}
\hline \multirow[b]{2}{*}{ Compound } & \multirow{2}{*}{$\begin{array}{l}\text { Amount } \\
\text { added } \\
\text { (ug.) }\end{array}$} & \multicolumn{2}{|c|}{$\begin{array}{l}\text { Relative fluorescent } \\
\text { intensity* }\end{array}$} & \multirow{2}{*}{$\begin{array}{c}\text { Recovery } \\
(\%)\end{array}$} \\
\hline & & $485 \mathrm{~m} \mu$ & $600 \mathrm{~m} \mu$ & \\
\hline Norepinephrine & 0.2 & 100 & 40 & 82 \\
\hline Epinephrine & 0.2 & 18 & 100 & 98 \\
\hline Isoprenaline & 0.2 & 45 & 100 & 90 \\
\hline Dopac & 0.2 & 23 & 8 & 95 \\
\hline Dopamine & 0.2 & 6.1 & 35 & 88 \\
\hline Dopa & 50.0 & 85 & 209 & 65 \\
\hline Catechol & 0.2 & 227 & 100 & 86 \\
\hline Phenol & 0.2 & 14 & 7 & 30 \\
\hline Pyrogallol & 0.2 & 3.6 & 25 & 50 \\
\hline
\end{tabular}

* Relative to fluorescence of norepinephrine at $485 \mathrm{~m} \mu$ and epinephrine at $600 \mathrm{~m} \mu$.

was accomplished by adsorption on activated alumina at $\mathrm{pH} 8.0$ to 8.5 , followed by elution with acetic acid. An Aminco-Bowman spectrophotofluorometer was used to measure fluorescence.

Blood specimens were drawn into heparinized tubes, centrifuged, and the plasma removed and immediately frozen. Five $\mathrm{ml}$. specimens of plasma were used for assays by the EDA condensation method. The lower degree of sensitivity of the trihydroxyindole method required larger plasma specimens for accurate determinations. One hundred $\mathrm{ml}$. of plasma was used for each determination in normal individuals and $30 \mathrm{ml}$. of plasma for assays in patients with renal disease.

Ethylenediamine method. The method of Weil-Malherbe and Bone $(2,3)$, as modified by Aronow and Howard (8), was used. Fluorescence of the condensation fluorophors was determined using an excitation wave length of $430 \mathrm{~m} \mu$ and fluorescent wave lengths of 485 and $600 \mathrm{~m} \mu$ for $\mathrm{NE}$ and $\mathrm{E}$, respectively. When the condensation fluorophor of $E$ is activated at $430 \mathrm{~m} \mu$ it produces a fluorescent peak at $520 \mathrm{~m} \mu$. However, in determining $\mathrm{E}$ in solutions containing both $\mathrm{E}$ and $\mathrm{NE}$, fluorescence at $600 \mathrm{~m} \mu$ is used because at this wave length the fluorescence of $\mathrm{E}$ exceeds that of $\mathrm{NE}$, and the separation of their respective fluorescent curves is maximal.

Trihydroxyindole method. The method of Lund (1), as modified by von Euler and Floding (9), was used. The intensities of fluorescence were determined using an excitation wave length of $415 \mathrm{~m} \mu$ and a fluorescent wave length of $515 \mathrm{~m} \mu$.

\section{RESULTS}

\section{Ethylenediamine method}

Standard solutions of the phenolic compounds, epinephrine, norepinephrine, isoprenaline (3,4dihydroxyphenyl- $\beta$-isopropyl-aminoethanol), dopa (3,4-dihydroxyphenyl- $\beta$-aminopropanoic acid), dopamine (3,4-dihydroxyphenyl- $\beta$-aminoethane), dopac (3,4-dihydroxyphenyl acetic acid), phenol, catechol, pyrogallol, $o$-cresol, $p$-cresol, phloroglucinol, quinol, tyrosine and serotonin (5-hydroxytryptamine) form fluorescent condensation products with ethylenediamine. Of these, only E, NE, isoprenaline, dopa, dopamine, dopac, phenol, catechol and pyrogallol are adsorbed from plasma by alumina. Recoveries of these compounds after addition of known amounts to plasma and assay by the EDA method are shown in Table I. Phenolic compounds which produce fluorescence with EDA but are not adsorbed from plasma by alumina are shown in Table II.

The fluorescent spectra of each of the compounds recovered from plasma were determined using an excitation wave length of $430 \mathrm{~m} \mu$. Dopac, catechol and phenol were found to have fluorescent maxima at 485, 485, and $480 \mathrm{~m} \mu$, respectively. These compounds, when present, will interfere mainly with the determination of $\mathrm{NE}$. Dopa, dopamine, isoprenaline and pyrogallol have fluorescent maxima at $520 \mathrm{~m} \mu$, the wave length of maximal fluorescence of $\mathrm{E}$. Therefore, if present in plasma, they will interfere mainly with the estimation of $\mathrm{E}$. However, because of some overlap of the fluorescent spectral curves of these compounds with those of both $\mathrm{E}$ and $\mathrm{NE}$, the presence of any of the compounds will interfere in the determination of either $\mathrm{E}$ or $\mathrm{NE}$.

Creatinine, urea, uric acid, indole and phosphate, all of which are found in increased quantities in the blood of uremic patients, were tested with the EDA reaction. Creatinine was the only one of these compounds that produced fluorescence; however, it is not adsorbed by alumina and therefore will not interfere with the determination of $\mathrm{E}$ and NE.

TABLE II

Compounds which produce fluorescence with ethylenediamine but are not adsorbed from plasma by alumina

\begin{tabular}{|c|c|c|c|c|}
\hline \multirow[b]{2}{*}{ Compound } & \multirow{2}{*}{$\begin{array}{l}\text { Amount } \\
\text { added } \\
(\mu g .)\end{array}$} & \multicolumn{2}{|c|}{$\begin{array}{c}\text { Relative fluorescent } \\
\text { intensity* }\end{array}$} & \multirow{2}{*}{$\begin{array}{l}\text { Recovery } \\
(\%)\end{array}$} \\
\hline & & $485 \mathrm{~m} \mu$ & $600 \mathrm{~m} \mu$ & \\
\hline$p$-cresol & 400 & 13 & 24 & 0 \\
\hline 0 -cresol & 100 & 4 & 3 & 0 \\
\hline Phloroglucinol & 100 & 32 & 95 & 0 \\
\hline Quinol & 0.2 & 100 & 90 & 0 \\
\hline Serotonin & 20 & 100 & 144 & 0 \\
\hline
\end{tabular}

* Relative to fluorescence of norepinephrine at $485 \mathrm{~m} \mu$ and epinephrine at $600 \mathrm{~m} \mu$. 
TABLE III

Plasma epinephrine and norepinephrine levels in patients with renal insufficiency as determined by the ethylenediamine condensation method

\begin{tabular}{|c|c|c|c|}
\hline Patient & $\mathrm{NE}$ & $\mathrm{E}$ & $\begin{array}{l}\text { Blood urea } \\
\text { nitrogen }\end{array}$ \\
\hline & \multicolumn{2}{|c|}{ 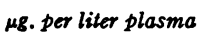 } & mg. per $100 \mathrm{ml}$. \\
\hline $\begin{array}{l}\text { E. R. } \\
\text { B. J. } \\
\text { R. B. } \\
\text { I. L. } \\
\text { M. V. } \\
\text { R. R. } \\
\text { M. O. } \\
\text { J. P. } \\
\text { B. F. } \\
\text { U. P. }\end{array}$ & $\begin{array}{r}8.3 \\
8.1 \\
6.5 \\
7.7 \\
3.4 \\
15.0 \\
8.4 \\
12.5 \\
15.1 \\
9.7\end{array}$ & $\begin{array}{l}0.8 \\
1.0 \\
1.5 \\
0.6 \\
3.8 \\
7.2 \\
1.4 \\
5.5 \\
1.9 \\
0.4\end{array}$ & $\begin{array}{r}220 \\
187 \\
159 \\
96 \\
55 \\
135 \\
150 \\
120 \\
95 \\
90\end{array}$ \\
\hline
\end{tabular}

Plasma $\mathrm{E}$ and $\mathrm{NE}$, as determined by the EDA method in a series of patients with renal insuffciency, are shown in Table III. In three of these patients both the $\mathrm{E}$ and $\mathrm{NE}$ values were elevated above the normal range. Six patients showed abnormal levels of the NE fraction alone, while one patient showed an abnormal elevation only in the $\mathrm{E}$ fraction. There was no correlation between the blood-urea-nitrogen levels and the level of elevation of $\mathrm{E}$ or $\mathrm{NE}$.

In three patients determinations were made before and after dialysis on the artificial kidney (Table IV). In two of these cases the elevated values before dialysis became normal following dialysis. In the third patient (E.H.) the NE level dropped to normal after dialysis but the $\mathrm{E}$ level remained elevated.

TABLE IV

Plasma epinephrine and norepinephrine levels in uremic patients before and after dialysis on the artificial kidney as determined by the ethylenediamine condensation method

\begin{tabular}{cccc}
\hline \hline Patient & NE & E & $\begin{array}{c}\text { Blood urea } \\
\text { nitrogen }\end{array}$ \\
\hline $\begin{array}{l}\text { E. H. } \\
\text { Before dialysis }\end{array}$ & $\mu g$. per liter plasma & $m g$. per $100 \mathrm{ml}$. \\
After dialysis & 13.0 & 3.8 & 200 \\
& 5.2 & 2.4 & 120
\end{tabular}

S. R.

Before dialysis After dialysis

$\begin{array}{ll}4.1 & 3.2 \\ 3.5 & 0.3\end{array}$

F. S.

Before dialysis After dialysis

$8.6 \quad 0.0$

$\begin{array}{ll}8.8 & 0.0\end{array}$

TABLE V

Trihydroxyindole method: Compounds which produce fluorescence

\begin{tabular}{|c|c|c|c|c|}
\hline \multirow[b]{2}{*}{ Compound } & \multirow{2}{*}{$\begin{array}{l}\text { Amount } \\
\text { added } \\
\text { (ug.) }\end{array}$} & \multicolumn{2}{|c|}{ \% oxidation } & \multirow{2}{*}{$\begin{array}{r}\text { Relative } \\
\text { fluorescen } \\
\text { intensity }\end{array}$} \\
\hline & & pH 3.5 & pH 6.5 & \\
\hline $\begin{array}{l}\text { Epinephrine } \\
\text { Norepinephrine } \\
\text { Isoprenaline } \\
\text { Dopamine }\end{array}$ & $\begin{array}{r}1.0 \\
1.0 \\
1.0 \\
10.0\end{array}$ & $\begin{array}{r}100 \\
4 \\
100\end{array}$ & $\begin{array}{l}100 \\
100 \\
100\end{array}$ & $\begin{array}{c}100 \\
73.6 \\
136 \\
0.5^{*}\end{array}$ \\
\hline
\end{tabular}

* Fluorescence occurs only at pH 6.5 .

\section{Trihydroxyindole method}

Epinephrine, norepinephrine, isoprenaline and, to a limited extent, dopamine, produced fluorescence with the trihydroxyindole method (Table $\mathrm{V})$. Isoprenaline is completely oxidized at both $\mathrm{pH} 3.5$ and 6.5 and will thus interfere with the determination of $\mathrm{E}$ only. Isoprenaline has a relative fluorescent intensity equal to $\mathrm{E}$ when activated at $415 \mathrm{~m} \mu$ with a fluorescence determined at 515 $\mathrm{m} \mu$. If isoprenaline is activated at $350 \mathrm{~m} \mu$, it will produce a fluorescent peak at $520 \mathrm{~m} \mu$, whereas $\mathrm{E}$ and $\mathrm{NE}$ have no fluorescence when excited at $350 \mathrm{~m} \mu$. Therefore, any interference due to the presence of isoprenaline could be detected in this manner.

Plasma $\mathrm{E}$ and $\mathrm{NE}$ levels as determined by both the EDA condensation and the trihydroxyindole methods in six normal individuals and five uremic patients are shown in Table VI. NE levels deter-

TABLE VI

Comparison of the ethylenediamine (EDA) condensation and the trihydroxyindole (THI) methods in normal individuals and patients with renal insufficiency

\begin{tabular}{|c|c|c|c|c|}
\hline \multirow[b]{2}{*}{ Subject } & \multicolumn{2}{|c|}{ EDA method } & \multicolumn{2}{|c|}{ THI method } \\
\hline & $\mathrm{NE}$ & $\mathrm{E}$ & $\mathrm{NE}$ & $\mathrm{E}$ \\
\hline Normal & \multicolumn{2}{|c|}{ 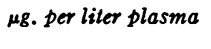 } & \multicolumn{2}{|c|}{ 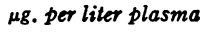 } \\
\hline $\begin{array}{l}\text { F. M. } \\
\text { E. R. } \\
\text { J. B. } \\
\text { F. R. } \\
\text { J. R. } \\
\text { J. F. }\end{array}$ & $\begin{array}{l}3.8 \\
2.2 \\
2.1 \\
2.6 \\
3.3 \\
2.2\end{array}$ & $\begin{array}{l}0.8 \\
0.6 \\
0.9 \\
0.4 \\
1.3 \\
0.3\end{array}$ & $\begin{array}{l}3.2 \\
2.0 \\
1.8 \\
1.7 \\
2.4 \\
2.1\end{array}$ & $\begin{array}{l}0.7 \\
0.1 \\
0.1 \\
0.1 \\
0.1 \\
0.1\end{array}$ \\
\hline \multicolumn{5}{|c|}{ Renal disease } \\
\hline $\begin{array}{l}\text { V. R. } \\
\text { U. F. } \\
\text { J. T. } \\
\text { M. S. } \\
\text { L. O. }\end{array}$ & $\begin{array}{r}6.5 \\
6.2 \\
8.7 \\
15.1 \\
8.4\end{array}$ & $\begin{array}{l}0.6 \\
0.9 \\
0.0 \\
0.0 \\
1.4\end{array}$ & $\begin{array}{l}2.1 \\
1.5 \\
3.0 \\
2.6 \\
2.2\end{array}$ & $\begin{array}{l}0.0 \\
0.9 \\
0.0 \\
0.15 \\
0.0\end{array}$ \\
\hline
\end{tabular}


mined by the EDA method were elevated in each uremic case; however, the $E$ levels in these five patients were within the normal range. Both $\mathrm{NE}$ and $\mathrm{E}$ were within the normal range when determined by the trihydroxyindole method.

\section{Sensitivity and normal values}

Addition and recovery experiments with the EDA method indicated that $0.08 \mu \mathrm{g}$. per liter of $\mathrm{E}$ and $\mathrm{NE}$ can be determined from eluates of $5 \mathrm{ml}$. of plasma. With this size plasma sample, $1 \mu \mathrm{g}$. per liter was the lowest concentration accurately determined by the trihydroxyindole method; therefore, larger specimens of plasma were used for this method as described above. In thirty normal subjects plasma $\mathrm{E}$ and $\mathrm{NE}$ determined by the EDA method gave a mean value for $\mathrm{E}$ of 0.47 $\mu \mathrm{g}$. per liter plasma, with a range from 0 to 1.5 ; for $\mathrm{NE}$ the mean value was $2.72 \mu \mathrm{g}$. per liter plasma, with a range from 1.5 to 4.5. In six normal subjects plasma $\mathrm{E}$ and $\mathrm{NE}$ determined by the trihydroxyindole method gave a mean value for $\mathrm{E}$ of $0.2 \mu \mathrm{g}$. per liter plasma, with a range from 0.0 to 0.7 ; for $\mathrm{NE}$ the mean value was $2.2 \mu \mathrm{g}$. per liter plasma, with a range from 1.7 to 3.2 .

\section{DISCUSSION}

The results indicate that the EDA reaction is not specific for $E$ and NE. All of the phenol compounds tested produce fluorophors with EDA whose spectra overlap the spectra of $E$ and NE. Therefore, if they are present in the blood, they could interfere with the fluorimetric determination of $\mathrm{E}$ and NE. However, only $\mathrm{E}, \mathrm{NE}$, isoprenaline, dopa, dopamine, dopac, phenol, catechol and pyrogallol are adsorbed from plasma by alumina.

The adsorptive properties of aluminum oxide, although not specific for the dihydroxy compounds as has been stated by von Euler and Orwen (10), limit the number of possible interfering substances for the EDA method. Phenol is the only monohydroxy compound that was adsorbed. Of the dihydroxy and trihydroxy compounds tested only those having a hydroxyl group in the ortho position were adsorbed by alumina.

Isoprenaline has been shown by paper chromatography to be present in the human adrenal medulla (11), but it has not been found in blood or urine. Dopamine (12) and dopac (13) have been identified in the urine and thus presumably are present in blood. Dopa has not been proved to be present in biological fluids. Other phenols occur in both blood and urine.

In the patient with normal renal function, the amount of interference from these substances, if present, would be small and relatively constant. However, in patients with renal insufficiency their excretion may be decreased with a resultant elevation in blood level. The presence of these or other interfering compounds in the blood could account for the high catechol amine levels observed in these patients.

The fact that the interference does not follow a definite pattern, occurring in both $\mathrm{E}$ and $\mathrm{NE}$ fractions in some cases and in the $\mathrm{E}$ or the $\mathrm{NE}$ fraction alone in other cases, suggests that more than one interfering substance is present. No single substance could account for these variations in interference. It is evident from the results obtained in patients with renal disease that the interfering substances are dialysable and that there is no relation between the degree of interference and the blood-urea-nitrogen levels. Although the identity of the interfering substances in these cases has not been established, it is possible that some of the compounds listed in Table I are involved.

The formation of fluorophors in the trihydroxyindole method requires the closure of the indole ring. Only isoprenaline was found to interfere to any significant degree with the estimation of $E$ and $\mathrm{NE}$ by this method. Since this substance has only been identified in the adrenal medulla where it constitutes less than one per cent of the total catechol amine present, the trihydroxyindole method can be considered a highly specific method of estimating $\mathrm{E}$ and $\mathrm{NE}$.

In the five patients with renal insufficiency, all of whom had elevated NE levels with the EDA method, the plasma $\mathrm{E}$ and $\mathrm{NE}$ were both within the normal range when determined by the trihydroxyindole method. Therefore, the substances present in the blood of uremic patients which interfere with the EDA method do not interfere with the trihydroxyindole method. In six normal individuals the plasma $\mathrm{E}$ and $\mathrm{NE}$ values determined by the trihydroxyindole method were slightly lower than those determined by the EDA method. The difference in values found in normal persons by the two methods, however, was not sufficient 
to account for the apparent differences in values found by these methods on plasma from patients with renal disease. This is further evidence that the elevated levels of $\mathrm{E}$ and $\mathrm{NE}$ determined by the EDA method in plasma of patients with renal insufficiency do not represent true values for $\mathrm{E}$ and $\mathrm{NE}$ but are due to the presence of interfering substances.

Valk and Price have recently shown that many of the phenolic compounds present in the blood and urine are capable of interfering with the EDA method (4). They were able to show a significant difference between normal plasma $\mathrm{E}$ and $\mathrm{NE}$ values determined by the EDA as opposed to the trihydroxyindole method. Although our results show that various phenolic compounds can interfere with the EDA method, we did not find a significant difference between the $\mathrm{E}$ and $\mathrm{NE}$ levels determined by the two methods in plasma of normal individuals. The discrepancies between the normal values by the THI method reported by Valk and Price and ourselves may be explained by the fact that these authors used smaller plasma samples for their determinations. The sensitivity of the THI method is such that there may be considerable error introduced if small plasma samples are employed. Our findings in plasma of normal subjects are in agreement with those of WeilMalherbe, who reports identical results with both methods (14).

\section{SUMMARY AND CONCLUSIONS}

1. The high plasma epinephrine and norepinephrine levels determined by the ethylenediamine condensation method in patients with renal insufficiency are not true values for epinephrine and norepinephrine and are due to the presence of substances in the blood of these patients which interfere with this method of assay.

2. The identity of the interfering substances has not been established; however, the phenolic compounds which occur in large quantities in the blood of patients with renal insufficiency may be involved.
3. The substances which interfere with the ethylenediamine determinations do not affect the determinations made with the highly specific trihydroxyindole method.

\section{REFERENCES}

1. Lund, A. Simultaneous fluorimetric determinations of adrenaline and noradrenaline in blood. Acta pharmacol. (Kbh.) 1950, 6, 137.

2. Weil-Malherbe, H., and Bone, A. D. The chemical estimation of adrenaline-like substances in blood. Biochem. J. 1952, 51, 311.

3. Weil-Malherbe, H., and Bone, A. D. The adrenergic amines of human blood. Lancet 1953, 1, 974.

4. Valk, A. de T., Jr., and Price, H. L. The chemical estimation of epinephrine and norepinephrine in human and canine plasma. I. A critique of the ethylenediamine condensation method. J. clin. Invest. $1956,35,837$.

5. Williams, R. T. Detoxication Mechanisms. The Metabolism of Drugs and Allied Organic Compounds. New York, John Wiley \& Sons Inc., 1947, p. 73.

6. Hoffman, W. S. The Biochemistry of Clinical Medicine. Chicago, The Yearbook Publishers, Inc., 1954 , p. 279.

7. Harrison, T. R., and Mason, M. F. The pathogenesis of the uremic syndrome. Medicine 1937, 16, 1.

8. Aronow, L., and Howard, F. A. Improved fluorometric technique to measure changes in adrenal epinephrine-norepinephrine output caused by veratrum alkaloids. Fed. Proc. 1955, 14, 315.

9. von Euler, U. S., and Floding, I. A fluorimetric micromethod for differential estimation of adrenaline and noradrenaline. Acta physiol. scand. 1955, 33, suppl. 118, 45.

10. von Euler, U. S., and Orwen, I. Preparation of extracts of urine and organs for estimation of free and conjugated noradrenaline and adrenaline. Acta physiol. scand. 1955, 33, suppl. 118, 1.

11. Lockett, M. F. Identification of an isoprenaline-like substance in extracts of adrenal glands. Brit. J. Pharmacol. 1954, 9, 498.

12. von Euler, U. S., and Hellner, S. Excretion of noradrenaline, adrenaline and hydroxytyramine in urine. Acta physiol. scand. 1951, 22, 161.

13. von Euler, C., von Euler, U. S., and Floding, I. Biologically inactive catechol derivatives in urine. Acta physiol. scand. 1955, 33, suppl. 118, 32.

14. Weil-Malherbe, $H$. The fluorimetric estimation of adrenaline and noradrenaline in plasma. J. Physiol. 1957, 135, 44P. 